\title{
Autonomia Criativa em Educação a Distância: Uso do Flipsnack em um Curso de Ciências Biológicas
}

\author{
Germana Costa Paixão*1, Ana Ciléia Pinto Teixeira Henriques², Francisco Fábio \\ Castelo Branco ${ }^{3}$, Eloisa Maia Vidal ${ }^{4}$, José Nelson Arruda Filho ${ }^{5}$
}

\footnotetext{
1 Coordenadora do Curso de Ciências Biológicas EAD/UAB/Universidade Estadual do Ceará, Vice-Líder do Grupo de Pesquisa Tecnologias Educacionais e Educação a distância. Av. Dr. Silas Munguba, 1700 Fortaleza - Ceará - Brasil. germana.paixao@uece.br

2 Tutora de pesquisa, Curso de Ciências Biológicas EAD/Universidade Estadual do Ceará, Av. Dr. Silas Munguba, 1700 - Fortaleza - Ceará - Brasil. anacileia.henriques@uece.br

3 Coordenador geral UAB/UECE, Secretaria de Apoio a Tecnologias Educacionais- Universidade Estadual do Ceará, Av. Dr. Silas Munguba, 1700 - Fortaleza - Ceará - Brasil. ffcastelo@terra.com.br

4 Coordenadora Adjunta UAB/UECE, Curso de Física /Universidade Estadual do Ceará, Av. Dr. Silas Munguba, 1700 - Fortaleza - Ceará - Brasil. eloisamvidal@yahoo.com.br

${ }^{5}$ Coordenador do Curso de Especialização em Gestão Pedagógica da Escola Básica EAD/UAB /Universidade Estadual do Ceará, Av. Dr. Silas Munguba, 1700 - Fortaleza - Ceará - Brasil. nelson.arruda@uece.br
}

\section{Resumo}

A aprendizagem autônoma é um dos fundamentos da educação a distância. Recursos tecnológicos importantes que permitem o desenvolvimento do poder de decisão e utilização de estratégias criativas devem ser estimulados para os alunos. Este é um estudo descritivo com abordagem qualitativa que descreve as experiências iniciais e as percepções de tutores sobre as dificuldades apresentadas pelos alunos com o uso de flipsnack, uma ferramenta que permite a criação e publicação de e-books, focando o desenvolvimento da criatividade e autonomia. Acredita-se que esta ferramenta vai contribuir para a formação acadêmica, oferecendo oportunidades para o desenvolvimento da autonomia criativa e seu papel fundamental na sua prática de ensino profissional.

Palavras-chave: Ensino; Educação a distância; Educação superior; Tecnologia da educação; Autonomia profissional. 


\title{
Creative Autonomy in Distance Education: Flipsnack Use in a Biological Sciences Course
}

\begin{abstract}
Autonomous learning is one of the foundations of distance education (DE). Important technological features that allow the development of power of decision and the use of creative strategies must be stimulating for the students. This is a descriptive study with a qualitative approach that describes the initial experiences and tutors' perceptions of difficulties presented by students with use of flipsnack, a tool that permits the creation and publication of e-books, which focuses on the development of creativity and autonomy. It is believed that this tool will contribute to academic training, providing opportunities for the development of creative autonomy and its fundamental role in their professional teaching practice.
\end{abstract}

Keywords: Teaching; Distance education; Higher education; Education technology; Professional autonomy. 


\section{Introdução}

A crescente necessidade de formação e capacitação de recursos humanos, a promoção do acesso à educação aos antes desprovidos deste direito devido às dificuldades temporais e espaciais contribuem para entender o significativo crescimento da Educação a Distância (EaD) no nosso país.

O fortalecimento desta modalidade ainda traz como marca o estímulo pela busca constante do desenvolvimento de habilidades como a autonomia e a criatividade do aprendiz, as quais, segundo Belloni (2002) e Jacobsen et al. (2011), compõem o perfil do aluno do século XXI.

Porém, Valente (2003) discute que esta reflexão ainda está centrada nos meios de comunicação e no material de apoio, sendo pouco discutidas as questões pedagógicas. O autor complementa que as propostas existentes têm prometido o desenvolvimento de habilidades e competências como autonomia, criatividade, aprender a aprender, porém que, claramente, não resistem à crítica do ponto de vista pedagógico, visto a carência de fundamentação neste sentido.

Visando à necessidade desta argumentação teórico-epistemológica, justifica-se a realização de estudos que busquem aprofundar os conceitos, definições e fundamentações pedagógicas da aplicação de recursos que visem ao alcance destas habilidades na EaD, para que, desta forma, modifique-se um perfil errôneo de pouco aprofundamento e baixa qualidade que ainda se tem desta modalidade em alguns contextos, passando a valorizá-la tal como é, com suas possibilidades e potencialidades educativas.

Tendo como foco o desenvolvimento de importantes habilidades que se esperam do aluno, em especial na EaD, a criatividade tem sido amplamente discutida, principalmente, em estudos de Psicologia, que têm abordado os fatores contextuais e pessoais que podem influenciar o desenvolvimento desta habilidade (Santeiro; Santeiro \& Andrade, 2004); (Fleith \& Alencar, 2006); (Alencar, 2002).

Santeiro, Santeiro e Andrade (2004) consideram que, nos mais diversos cenários, a criatividade tem sido reconhecida como de relevância para o desenvolvimento e compreensão do ser humano e de suas manifestações, devendo esta ser entendida levando-se em conta, desde características intrínsecas da pessoa 
criativa (personalidade, habilidades cognitivas) até o ambiente mais amplo onde esta se insere (família, escola, trabalho), atuando estas instâncias reciprocamente umas sobre as outras.

Fleith e Alencar (2006) reforçam que, com o avanço das pesquisas na área de criatividade, o foco passou das habilidades cognitivas e traços de personalidade, fatores puramente individuais, que remetem para a possibilidade inata e própria do sujeito criativo, para a relação entre fatores sociais, culturais e históricos e o desenvolvimento da expressão criativa, mudando-se, desta forma, o foco de fatores internos para condições externas que possam potencializar esta expressão.

Santeiro, Santeiro e Andrade (2004) afirmam que os indivíduos criativos desejam e buscam o crescimento sem travar lutas com as novas ideias que surgem nesse processo, tendo o potencial de fazê-las "brotar", fomentando-as. Para esse fim, considerando o contexto educacional, podem ser utilizadas diversas ferramentas que tenham como fundamentação teórico-pedagógica e metodológica em sua construção e utilização a busca do desenvolvimento da mente criativa e da autonomia dos discentes.

Estudo realizado por Fleith e Alencar (2006) indica que o desenvolvimento da autonomia do aluno encontra-se prejudicada na educação brasileira com resultados apontando que o encorajamento desta característica de personalidade não parece ser o foco no ensino presencial. Nota-se que o processo de ensino e aprendizagem ainda está centralizado na figura do professor, ou seja, é ele quem planeja, escolhe, decide e avalia o que será implementado em sala de aula.

Contextualizando o desenvolvimento desta habilidade na EaD, visualizam-se suas potencialidades, já que, como afirmam Jacobsen et al. (2011), nesta modalidade, o nível de autonomia conferido ao aluno é superior, se comparado à modalidade presencial, pois o aluno passa a ser o principal gestor do próprio processo de aprendizagem, e o professor assume o papel de orientador e mediador.

Os autores acrescentam que a atual geração de EaD e seus ambientes de desenvolvimento exigem o pleno engajamento do aluno, reconhecendo-o como um indivíduo que tem potencial para ser um mestre de si mesmo em relação ao seu próprio destino. Nesse contexto, o professor torna-se o mentor do aluno, servindo 
como um consultor de conteúdos, motivador e integrador do contexto, assim como um gestor participante da experiência de aprendizado (Jacobsen et al., 2011).

Neste momento, no qual se demandam mudanças urgentes e amplas na educação, o docente pode fazer uso de estratégias mediadoras, a fim de se deslocar da figura central do processo ensino-aprendizagem, e conferir este papel ao aluno.

Essas estratégias são ressaltadas, visto que, conforme compreendem e discutem Rocha e Vilarinho (2008), o desenvolvimento da autonomia ultrapassa os sistemas educativos distanciados do cotidiano, preocupados apenas com conteúdo e produto final, nos quais a fragmentação e a hierarquização de saberes e disciplinas se refletem na prática pedagógica em detrimento do processo de construção do conhecimento.

É esse o caminho a ser alçado pela EaD, afastando-se de modelos pedagógicos que ainda persistem em diferentes contextos, os quais, embora mediados pela tecnologia e recursos digitais, centram o uso das ferramentas e a construção dos produtos no professor, dando a sensação de uma "falsa" autonomia.

Essa afirmação vai de encontro com o que afirma Rezende (2002), ao ressaltar que os meios, por si sós, não são capazes de trazer contribuições para a área educacional e que eles são ineficientes se usados como o ingrediente mais importante do processo educativo, ou sem a reflexão humana, reforçando que a tecnologia educacional deve adequar-se às necessidades de determinado projeto políticopedagógico, colocando-se a serviço de seus objetivos e nunca os determinando.

Assim, reforça-se o papel da Universidade e das práticas que ocorrem em seu ambiente como importante locus para possibilidade de desenvolvimento da criatividade e autonomia do indivíduo, devendo-se, desta forma, utilizar de práticas, ferramentas e ações que potencializem esta construção.

Dentre essas estratégias destaca-se o livro digital ou, também anglicanamente denominado e-book, caracterizado pela Câmara Técnica de Documentos Eletrônicos do Conselho Nacional de Arquivos (CONARQ) por sua característica de codificação em dígitos binários e pelo acesso através de um sistema computacional e que assume importante magnitude no contexto social e educacional atual (CONARQ, 2014). 
Dourado e Oddone (2012) defendem que o livro digital emerge como fenômeno cultural e alcança popularidade enquanto artefato de consumo, por sua capacidade de disseminar o conhecimento de maneira ágil e rápida, tornando-o o recurso mais adequado às demandas do cenário contemporâneo.

Discussões têm sido promovidas na conjuntura de transição do livro impresso para o livro digital, procedimento que parece buscar a transferência do prestígio e valor perante a sociedade conquistados pelo primeiro para os "livros" digitais e eletrônicos, de modo a tornar natural a inserção sociotécnica desses novos objetos e a evitar os desconfortos do processo de transição e mudança para o ambiente digital, discutindose sobre a arquitetura destes novos objetos de consumo (Dourado \& Oddone, 2012).

Considerando-se o perfil do público-alvo desses recursos, analisa-se que os ebooks educativos atendem, em sua maioria, um público nascido e criado no meio digital, familiarizado diariamente com mídias diversas estimulando todos os sentidos, logo acredita-se que essa mudança arquitetural não impacte na aceitação desses recursos, pelo contrário, estimule a substituição do livro impresso pelo digital, considerando, inclusive, a possibilidade de produção deste por parte deste aluno.

Flatschart (2014) já considera essa possibilidade rica de componentes nos ebooks ao defini-los como um livro que normalmente contém textos e imagens, mas, não raro, recursos de multimídia e interatividade.

Nesse contexto, assumem relevância os recursos tecnológicos que permitem o desenvolvimento da capacidade de escolha e de decisão de inclusão desses recursos na produção de e-books, além de instigar o uso de estratégias criativas nesse processo, motivando o aluno em relação à construção da aprendizagem autônoma a distância, através da produção de seus próprios livros digitais.

Fundamentando-se na importância da utilização de novas tecnologias educativas multimídias, o Flipsnack ${ }^{\circledR}$ caracteriza-se como recurso interativo disponível on-line, que permite a edição e publicação de flipbooks, livros ou folhetos interativos.

Trata-se de software gratuito (http://www.flipsnack.com/br/), sem obrigatoriedade de registro, cujo acesso se faz através de contas de e-mail gratuito (Gmail) ou redes sociais $\left(\right.$ Facebook $^{\circledR}$ e Twitter $^{\circledR}$ ), desenvolvido, a princípio, para divulgação de conteúdo comercial. Apresenta diversos recursos de customização, com 
inclusão de vídeos, som e outras mídias interativas, links para outros conteúdos relacionados e facilidades para divulgação do flipbook.

Nele, o aluno pode iniciar sua produção a partir de um arquivo em extensão ".pdf", previamente produzido e formatado em arquivos de texto como o Microsoft Word, assim como em formato ".jpg", no caso da construção de álbuns com imagens, através da função START FR FROM PDF/JPG e, posteriormente, inserir os recursos no próprio site.

O software também oportuniza a produção inteira com os recursos do próprio site, através da função START FROM SCRATCH, com a qual o aluno poderá selecionar as fontes e tamanhos de letra de seu flipbook, o layout de disposição do conteúdo, ações de páginas, inserção de hyperlink, áudios e vídeos, imagens de sua biblioteca ou escolher no próprio site no banco de imagens disponíveis, ícones, ilustrações e customizar a capa ao final da produção.

Visualizando-se todas as possibilidades de construção dos e-books com uso do Flipsnack ${ }^{\circledR}$ e compreendendo a importância do compartilhamento de experiências de tutores no uso de ferramentas tecnológicas, realizou-se estudo descritivo-reflexivo, com abordagem qualitativa, apresentando o uso do flipsnack em atividades adicionais no Ambiente Virtual de Aprendizagem (AVA) Moodle no qual se desenvolvem as atividades do curso de Licenciatura em Ciências Biológicas EAD-BIOEAD da Universidade Estadual do Ceará-UECE em parceria com a Universidade Aberta do Brasil-UAB.

A relevância do relato de experiência baseia-se na pertinência e importância dos problemas que nele se expõem, assim como o nível de generalização na aplicação de procedimentos ou de resultados da intervenção em outras situações similares, servindo como uma colaboração à práxis metodológica da área à qual pertence.

São descritas a seguir as experiências de três tutores a distância, as percepções quanto às dificuldades apresentadas pelos alunos no uso inicial da ferramenta e de propostas de utilização da mesma com intuito do desenvolvimento das habilidades de autonomia e criatividade dos educandos. 


\section{Resultados da investigação}

A ferramenta Flipsnack ${ }^{\circledR}$ foi utilizada por dois semestres letivos, nas disciplinas Estágio Supervisionado no Ensino Médio 2- ESEM 2 e Língua Brasileira de SinaisLibras, cursadas pelos alunos dos polos de apoio presencial dos municípios de Beberibe e Aracoiaba, ambos no Ceará. Na primeira disciplina, os alunos foram instigados a produzir um texto original, didático e dinâmico, com a inclusão de ilustrações e componentes gráficos, posteriormente convertendo-o em formato ".pdf", única extensão aceita para conversão no flipsnack quando o arquivo de texto está pronto para ser convertido no software, sendo produzidos 18 flipbooks.

Os tutores a distância, responsáveis pela avaliação da atividade, não identificaram maiores dificuldades por parte dos alunos nesse processo, visto que foi indicado tutorial com informações básicas sobre o manejo da ferramenta, além do esclarecimento das dúvidas por meio dos fóruns de interação disponíveis no AVA Moodle.

A disponibilização dos flipbooks produzidos para compartilhamento entre os alunos no Moodle foi um dos questionamentos surgidos, porém o tutorial apresenta esta possibilidade através do compartilhamento do link gerado no próprio site.

A experiência repetiu-se com a disciplina de Libras, na qual a orientação foi direcionada para construção de texto sobre Educação de surdos no Brasil, com extensão de no máximo duas laudas, sendo produzidos 32 e-books nessa atividade. Porém, como não ocorreu instrução quanto à inserção de recursos gráficos nessa atividade, 25 e-books (78,1\%) não utilizaram nenhum recurso visual para enriquecer a produção escrita.

Essa não inclusão de recursos gráficos não descaracteriza o e-book, visto que, originalmente e conceitualmente, o mesmo consta com informações escritas em sua essência, mas pode ter prejudicado o desenvolvimento dessa habilidade criativa nos alunos.

Dessa forma, compreende-se a importância do fornecimento de diretrizes claras para a produção e avaliação dos e-books produzidos, facilitando a organização do processo de construção por parte do aluno, mas tendo o cuidado de não tolher sua 
autonomia, permitindo que o mesmo inove, invente, crie e seja seu próprio mestre na produção criativa.

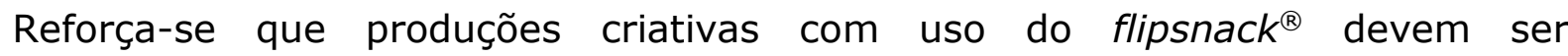
estimuladas na composição da aprendizagem, pois, como afirma Becker (2002), esta se constrói na ação do sujeito por meio das ações que ele mesmo pratica.

Rocha e Vilarinho (2008) reforçam que a aprendizagem é um processo de construção e não de reprodução, por isso não se aprende o que não se assimila, o que é apenas decorado ou memorizado. Aprende-se quando, internamente, o sujeito se dispõe a tal, decidindo, por conta própria, aprender.

A ferramenta possibilita a produção escrita, a inclusão de elementos gráficos, o acréscimo de movimento às páginas e permite a customização com diferentes layouts de capa, animações de áudio e vídeo, e links para e-mails e redes sociais, como consequência visualiza-se que a utilização deste software como recurso para produção acadêmica, em especial, na instrumentalização da produção textual e como possibilidade de estratégia avaliativa.

Embora cientes de que alguns alunos podem vivenciar dificuldades iniciais no uso da ferramenta, as poucas dificuldades relatadas pelos alunos no curso de Ciências Biológicas - EaD que a utilizaram demonstram que a mesma é acessível, bastando disponibilizar informações claras sobre seu manejo e que seja proporcionado apoio mútuo entre tutores e alunos, de modo que os aprendizes sintam-se ã vontade em questionar, sanar suas dúvidas e aprender juntos nesse caminho.

Fleith e Alencar (2006) ao abordarem as características propiciadoras de uma atmosfera criativa no contexto educacional, elencam algumas considerações importantes ao relacioná-las ao uso do flipsnack e seus recursos.

Os autores consideram que essa atmosfera visa desenvolver o senso crítico e a independência de pensamento dos alunos, o que é possibilitado através da construção do flipbook, onde o aluno é responsável pela escolha do conteúdo, a partir de uma temática predeterminada na disciplina, e, com esta, é livre para buscar as fontes, selecioná-las e sistematizar o conhecimento acessado de forma didática e atrativa. 
Outro fator, visualizado com o uso do flipsnack ${ }^{\circledR}$, e condizente com a construção de uma atmosfera criativa, consiste em incentivar e orientar os alunos a buscarem informações adicionais sobre assuntos de seu interesse, incrementando seu flipbook com mídias de áudio, vídeo, imagens, links, acesso a conteúdo adicional, todos escolhidos como produto de seu processo criativo.

Considerando as características do software Flipsnack ${ }^{\circledR}$ e seu potencial para uso na educação e buscando fundamentação em resultados de estudos que apontam que o contexto de aprendizagem deve oferecer oportunidades de escolha, aceitar diferentes ideias e focalizar os interesses do aluno, visualiza-se claramente a concordância dessa proposta no sentido do desenvolvimento da autonomia criativa do aluno (Fleith \& Alencar, 2006).

Preconiza-se, dessa forma, a visão apresentada por John Dewey, filósofo norteamericano, que aborda uma aprendizagem fundamentada no princípio "aprender a fazer, fazendo", segundo a qual, a aquisição de conhecimentos se dá por meio do que chamou de continuum experiencial (Rocha \& Vilarinho, 2008).

Acredita-se que, com uso do Flipsnack $^{\circledR}$ e a produção de flipbooks no curso de Ciências Biológicas na modalidade a distância, a partir das experiências observadas e analisadas neste estudo, possa-se estimular docentes e discentes a valorizarem o modelo educacional, descentralizado do professor para o aluno, do produto para o processo, da valorização formativa unicamente cognitiva para a relacional e cidadã.

Fundamenta-se, portanto, pedagogicamente, os pressupostos da epistemologia construtivista, a qual, segundo Rezende (2002), relaciona-se com a ideia de construção, traduzida na criação de ambientes de aprendizagem que permitam e deem envolvimento ativo do estudante na realização de uma tarefa, além de sua contextualização, oferecendo para isso ferramentas e meios para criação e manipulação de artefatos ao invés da apresentação de conceitos prontos ao estudante.

O aluno como produtor e divulgador do conhecimento poderá se sentir mais valorizado e fundamental nesse processo que, até então, poderia fazê-lo como ser passivo ou espectador. Assumem-se, dessa forma, novos contornos no contexto educacional, que saiam do papel e do campo teórico e caminhem para a práticaem direção a uma nova visão de educação. 


\section{Definição do alcance do trabalho, relevância do resultado produzido e seu aporte à realidade nacional, regional ou local}

Acredita-se que a ferramenta Flipsnack $®$ contribui para a formação do aluno, oportunizando o desenvolvimento da autonomia criativa, tendo este papel fundamental em sua futura prática profissional docente, que deve se basear na formação de professores mais críticos, criativos e produtores de ferramentas educacionais.

Formar professores que exercitarão durante toda sua formação essa mudança, e serão potenciais multiplicadores desses referenciais pedagógicos, contribui para a renovação do modelo educacional vigente.

Entendendo o papel da educação para além de seu papel de formação técnica, valoriza-se sua função como fomentadora da atitude criativa descrita por Feldman, Ruthes e Cunha (2008) sobre a qual afirmam que vem de uma necessidade inerente a todo o ser humano de crescer através de seu potencial interno.

Enfatizando o desenvolvimento da criatividade, justifica-se o uso da ferramenta de produção de e-books, visto que, segundo Alencar (2002), a criatividade é uma habilidade que deve ser incentivada na promoção do bem-estar emocional causado por experiências de aprendizagem criativa, contribuindo para melhor qualidade de vida das pessoas e por auxiliar na formação profissional, uma vez que a criatividade se apresenta como característica fundamental, que ajuda o indivíduo a lidar com as adversidades e desafios impostos pelo nosso tempo.

Assim, os alunos devem ser devidamente instrumentalizados e estimulados para, mesmo nas salas virtuais, desenvolverem a almejada autonomia e criatividade, vencendo um dos desafios da EaD como modalidade educacional, visto que pesquisas apontam que docentes e discentes apresentam diferentes percepções de práticas que contribuem para o desenvolvimento do potencial criativo (Alencar \& Fleith, 2004).

Em concordância, Rocha e Vilarinho (2008) afirmam que o professor tem papel de destaque nessa tessitura ao se configurar como mediador pedagógico capaz de estimular e desafiar o aluno a construir novos saberes seja individual ou coletivamente. 
Dessa forma, reforça-se a importância de orientações claras e objetivas dos professores/tutores aos alunos na utilização de uma nova ferramenta tecnológica, possibilitando aos mesmos a escolha dos recursos disponíveis e sua efetiva construção criativa, fundamentada não naquilo que foi determinado pelo professor, mas fruto de suas escolhas conscientes, acordadas com os colegas (no caso de produções coletivas), resultando em produtos finais com a marca pessoal do aluno, contribuindo, inclusive para melhorar sua autoestima e percepção da importância do seu processo de aprendizagem.

\section{Conclusões}

Ressaltamos a valorização da ferramenta Flipsnack ${ }^{\circledR}$ como mediadora do processo pedagógico em cursos de graduação a distância, no sentido da instrumentalização da produção textual, porém há necessidade de maior envolvimento da interação tutor-aluno, com vistas a produções dinâmicas, críticas e que busquem além do desenvolvimento de habilidades cognitivas.

Visualizamos um novo horizonte de utilização de livros digitais em complementação aos impressos, considerando a facilidade de acesso aos mesmos por meio dos repositórios digitais e pela própria produção de discentes, avaliando-se cuidadosamente os produtos desta produção quanto ao conteúdo, pertinência, rigor metodológico e crítica teórica.

\section{Agradecimentos}

Agradecemos o apoio financeiro da Universidade Aberta do Brasil que fomenta a oferta do Curso de Ciências Biológicas EAD da Universidade Estadual do Ceará.

\section{Referências bibliográficas}

Alencar, E. M. L. S. (2002). O contexto educacional e sua influência na criatividade. Linhas Críticas, 8, 165-178. 
Alencar, E. M. L. S., Fleith, D. S. (2004). Creativity in university courses: Perceptions of professors and students. Gifted and Talented International, 19, 24-28.

Becker, F. (2002). Construtivismo: apropriação pedagógica. In: Rosa, D. E. G., Souza, V. C. Didática e práticas de ensino: interfaces com diferentes saberes e lugares formativos. Rio de Janeiro: DP\&A.

Belloni, M. L. (2002). Educação a distância. São Paulo: Autores Associados.

CONARQ (2014) Câmara Técnica de Documentos Eletrônicos. Perguntas mais frequentes: documento digital é a mesma coisa que documento eletrônico? Acesso em: 06 nov. 2014, disponível em http://www.documentoseletronicos.arquivonacional.gov.br/cgi/cgilua.exe/sys/st art.htm

Dourado, S.M., Oddone, N.E. (2012) A arquitetura do livro digital na Plataforma Google: um estudo exploratório. Enc. Bibli: R. Eletr. Bib. Ci. Inf., 17(34),131141.

Feldman, L.B., Ruthes, R.M., Cunha, I.C.K.O. (2008) Criatividade e inovação: competências na gestão de enfermagem. Rev Bras Enferm, Brasília, 61(2): 239242.

Fleith, D.S., Alencar, E.M.L.S. (2006) Percepção de alunos do ensino fundamental quanto ao clima de sala de aula para criatividade. Psicologia em Estudo, Maringá, 11(3), 513-521. Parei aqui

Fletschart, F. (2014) Livro digital etc. Rio de Janeiro: Brasport.

Jacobsen, A.L. et al. Autonomia do aluno na educação a distância: o caso do curso de administração a Distância da UFSC. (2011). Revista Gestão Universitária na América Latina - GUAL, 4(2), 53-73.

Rezende, F. (2002) As novas tecnologias na prática pedagógica sob perspectiva construtivista. ENSAIO - Pesquisa em Educação em Ciências. 2(1), 1-18.

Rocha, A.C., Vilarinho, L.R.G. (2008). Educação online: um caminho para a construção da autonomia? Linhas Críticas, 14 (27), 247-261. 
Santeiro, T.V., Santeiro, F.R.M., Andrade, I.R. (2004) Professor facilitador e inibidor da criatividade segundo universitários. Psicologia em Estudo, Maringá, 9(1), 95102. 